\title{
Articles
}

\section{Intragroup Socialization for Adult Korean Adoptees: A Multigroup Analysis}

\author{
Kimberly J. Langrehr*a, Deborah Napier ${ }^{b}$ \\ [a] School of Education, University of Missouri - Kansas City, Kansas City, MO, USA. [b] Eastern Washington University, Cheney, WA, USA.
}

\begin{abstract}
The purpose of the current study was to test a model of socialization among a sample of adult Korean adoptees. Based on the tenants of homophily and social identity theory, it was hypothesized that participants' early racial and ethnic socialization experiences would account for their current intragroup friendships as adults, and that this relationship would be mediated by early intragroup contact and moderated by early ethnic identity status. The two ethnic and racial socialization variables (i.e., ethnic heritage activities and racial in-exposure) significantly accounted for participants' relationships with other Korean adoptees and nonadopted Koreans, and the effects were partially explained by early intragroup contact. Results of multigroup testing indicated the proposed socialization model was non-invariant across groups, such that the effects of ethnic heritage activities on intragroup contact and the effect of racial in-exposure on friendships with Korean adoptees were significantly different based on early ethnic identity status.
\end{abstract}

Keywords: Korean adoptees, transracial adoption, intragroup socialization, ethnic identity

Interpersona, 2014, Vol. 8(1), 15-31, doi:10.5964/ijpr.v8i1.155

Received: 2014-02-06. Accepted: 2014-04-25. Published (VoR): 2014-06-27.

*Corresponding author at: Counseling and Educational Psychology Program, School of Education, University of Missouri - Kansas City, 215 Education building 5100 Rockhill Road, Kansas City, MO 64110. E-mail: langrehrk@umkc.edu

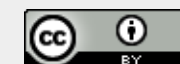

This is an open access article distributed under the terms of the Creative Commons Attribution License

(http://creativecommons.org/licenses/by/3.0), which permits unrestricted use, distribution, and reproduction in any medium, provided the original work is properly cited.

In the United States, issues related to diversity and multiculturalism are becoming increasingly complex. Although traditionally viewed as a between-group phenomenon, the concept of diversity also applies to unique and intersecting identity statuses and within-group variation. Greater appreciation of within, or intragroup differences may be particularly helpful for expanding social views toward populations who are often overgeneralized as homogenous in nature (Tajfel, 1981). For example, members of racial and ethnic minority groups can vary considerably in their experiences with socialization and identity development. For individuals who differ from traditional expectations associated with their group, their process with identity development can be even more complex and/or misunderstood.

This study focuses on the social-developmental significance of ethnic identity among a sample of adult Korean adoptees (KADs), one of several subgroups within the Korean and larger Asian American community. In the United States, the majority of KADs are considered transracial such that their phenotype is unmistakably different from their adoptive parents, as most are adopted into White families (Baden, 2002; Lee, 2003). Given that differences are visible within multiracial networks (Herman, 2004), KADs face unique socialization experiences that differ from the social trajectory of individuals raised in monoracial/ethnic families. The underlying tenants of social and ethnic identity theories are difficult to fully apply to KADs' and their experiences given the assumption that 
primary and early socialization takes place in the context of families with shared demographical characteristics, namely race and ethnicity. Transracial KADs may face a unique set of encounters throughout their identity development, given that interracial contact is a normative process in their adoptive families, whereas contact with other Koreans or Asian Americans typically occurs outside of the home. At the same time, little is known about KADs' experiences with intragroup socialization beyond the adoptive family context. Research suggests that in general, people tend to gravitate toward others who are similar in values, beliefs, and lifestyles (Goldman, 1981; Matthews, 1995; McCandless \& Hoyt, 1961). According to the principle of homophily (Hamm, 2000; McPherson, SmithLovin, \& Cook, 2001) and social identity theory (Tajfel \& Turner, 1986), spending time with similar others can reinforce a person's sense of collective identity, which can strengthen their need for intragroup contact. In this study, we focus on KADs, a subgroup of Asian Americans and their early racial and ethnic socialization experiences as transracial adoptees. Considering that a person's identity can clearly influence their behavior (Abrams, 1996; Brewer, 1991; Tajfel, 1981) and relationships across the life-span (Wood \& Pannen, 1996), we are interested in whether KADs' early ethnic identity status makes a difference in their intragroup socialization process despite their unique encounters as transracial adoptees.

\section{KADs, Ethnic Identity, and Influence of Cultural Socialization}

As one of the first and largest cohorts of infants and children adopted by American families, KADs account for a large proportion of the adult international and transracial adoption community. Beginning in 1953, Korea has sent an estimated 100,000 to 300,000 infants and children to the United States for adoption (Freundlich \& Lieberthal, 2000; National Association of Korean Americans, n.d.). In contrast to a more traditional immigrant experience, most KADs are afforded the benefits of growing up in stable, middle-class, White families. As a result, KADs are highly assimilated into American culture and share similar values and belief systems with that of their White peers (Lee, 2003; Wickes \& Slate, 1996). It is because of this assimilation, however, that KAD's often face the transracial adoption paradox where families and peers view them as White or simply American; yet as visible racial minorities in the greater context of society, they are unable to pass as members of the racial majority (Lee, 2003).

Overall, studies have found that KADs vary in their self-ascribed ethnic identity status (Baden, 2002; Lee, 2003), which can range from feeling secure (Simon \& Altstein, 2000; Wickes \& Slate, 1996) to feeling uncomfortable with their ethnic appearance (Brooks \& Barth, 1999; Meier, 1999; Westhues \& Cohen, 1998). Over the past decade, research on transracial adoption has examined socio-cultural factors that may account for this variation in ethnic identity, by focusing on racial and cultural socialization within the adoptive family context (Lee, Grotevant, Hellerstedt, Gunnar, \& The Minnesota International Adoption Project Team, 2006). For transracial adoptees, in particular, studies have defined cultural socialization as adoptive parents' deliberate efforts to involve their children in activities such as culture camps, language classes, and attending ethnic churches and restaurants (Lee et al., 2006; Scroggs \& Heitfield, 2001). Although viewed as culturally generic and appropriated (McGinnis, Smith, Ryan, \& Howard, 2009; Samuels, 2009); there is some evidence to suggest that KADs, who are exposed to aspects of their culture tend to report stronger ethnic identity as children (Lee \& Quintana, 2005; Yoon, 2000) and as adults (Mohanty, Keokse, \& Sales, 2006).

\section{Significance of Intragroup Socialization on Identity}

Most research on socialization among KADs and other transracial adoptees has been within the adoptive family context without addressing their out-group status as racial and ethnic minorities in the greater scope of society. Specifically, few studies have addressed the influence of socialization factors beyond the direct impact of adoptive parents' efforts to expose their children to aspects of their culture. Of the limited number of studies on adult KADs, 
findings confirm that most are raised in White homogenous environments and have faced minimal opportunities to interact with people of color (Feigelman, 2000; Langrehr, Yoon, Hacker, \& Caudill, in press). Many adult KAD's have attributed their experiences with racial inexposure to the geographic residence of their adoptive families (Shiao \& Tuan, 2008). For people of socially marginalized status, opportunities to engage with similar others can play a significant role in how they conceptualize their identity in relation to others (Clark \& Ayers, 1992; Hogg \& Abrams, 1988; Howes \& Wu, 1990). For example, compared to children from monoracial/ethnic families, transracial adoptees raised in primarily White communities have described more discomfort with their racial appearance (Feigelman, 2000) and a limited desire to associate with their racial or ethnic group (Huh \& Reid, 2000). In contrast to most families of color where members share the same racial and ethnic background, KADs rely on non-familial experiences for ethnic and racial socialization, often found in peer groups and neighborhood exposure (Herman, 2004; Umaña-Taylor \& Fine, 2004). For KADs with limited cultural exposure, it is likely that opportunities to engage in intragroup socialization may help facilitate a greater understanding of themselves in relation to other Koreans, Asian Americans, and people of color.

\section{Intragroup Friendships}

Despite their adoption into White American families, KADs remain visible racial and ethnic minorities in the context of American society. As a result, KADs face certain encounters similar to that of their ethnic minority peers; including racial discrimination (Meier, 1999), identity confusion (Kim, Suyemoto, \& Turner, 2010), and navigating multiple identities (Lee, 2003). As youth of color, KADs may also prefer to spend time with Korean or other same-race peers (Hamm, 2000; Tatum, 1999); a preference common for adolescents (Goto, 1997). Multiple studies suggest that throughout the lifespan, people prefer to engage in relationships with others who share similar lifestyles, backgrounds, and interests (Goldman, 1981; Matthews, 1995; McCandless \& Hoyt, 1961). Also known as homophily, this principle helps organize societal structures based on factors, such as age, sex, race/ethnicity, education, and psychological characteristics (McPherson et al., 2001). For minority individuals, connecting with similar others can become an adaptive experience (Adams, 1987; Hartup \& Stevens, 1997; Hess, 1972; Hochschild, 1973) that can mitigate stresses associated with marginalized identity status (Connidis \& Davies, 1992; Phinney, Romero, Nava, \& Huang, 2001).

The principle of homphily and social identity theory can be used to explain the growing nature of the adult KAD community over the last two decades. Based on their shared and unique experiences, adult KADs have connected with another, forming worldwide organizations to provide advocacy and support for KADs and other transracial and international adoptees (Hübinette, 2004; Lee \& Miller, 2009). Such organized efforts have enabled KADs to build and sustain a sense of community that provides social networking opportunities, considered essential for people to achieve a deeper understanding and appreciation of their group membership (Clark \& Ayers, 1992; Hogg, Abrams, \& Patel, 1987). Despite an increased sense of community, some adult KADs choose to connect with one another whereas others do not. Based on the underpinnings of social identity theory (Tajfel \& Turner, 1986), and the principle of homophily (McPherson et al., 2001), maintaining within-group preferences would typically be expected among racial and ethnic minority group members; however, it is unknown whether this concept applies to KADs considering that the nature of their early socialization experiences take place within the context of White American families. Overall, viewpoints coincide that a person's social identity can clearly influence their behavior (Abrams, 1996; Brewer, 1991; Tajfel, 1981; Tajfel \& Turner, 1986) and relationships across the life-span (Hartup \& Stevens, 1997; Wood \& Pannen, 1996); therefore, it is important to examine the role of identity status in this socialization process particularly among a sample of KADs given that intergroup contact (with adoptive 
family members) tends to be a normative process. It is likely that early contact with KADs and nonadopted Koreans will be significant in explaining their process of socialization.

\section{Purpose of the Current Study}

The purpose of the current study is to test a model of socialization that examines the influence of KADs' early ethnic and racial socialization on their current adult intragroup friendships. Based on the principle of homophily (Hamm, 2000; McPherson et al., 2001) and social identity theory (Tajfel \& Turner, 1986), we first propose that KADs' early racial and ethnic socialization experiences will account for their friendships with other KADs and nonadopted Koreans as adults. Given that cultural socialization has been found to be important in the socioemotional development for KADs (Lee \& Quintana, 2005; Yoon 2000), we anticipate that they, in some way, have been influenced by early engagement in ethnic heritage activities. We are also interested in the impact of early racial in-exposure, given that KADs and other transracial adoptees have had varying degrees of contact with people of color (Feigelman, 2000; Langrehr et al., in press). According to social identity theory (Tajfel \& Turner, 1986), minimal contact with in-group members (and on-going contact with out-group members) can also impact the way that people view themselves in relation to similar others. Second, we focus on the mediating role of early intragroup contact in explaining this relationship considering that spending time with similar others may have reinforced their desire to seek out intragroup relationships. We hypothesize that KADs' early racial and ethnic socialization experiences will account for their early intragroup contact, which will in turn, explain their current friendships with other KADs and nonadopted Koreans. And third, given that early group identification can make a difference in the way that people conceptualize themselves in relation to similar others (Hogg \& Abrams, 1988), we propose that this model of socialization will function differently depending on participants' early ethnic identity, such that the model will be non-invariant across the two groups of participants who either identified as Korean growing up or did not identify as Korean. These aspects of socialization may be particularly salient for populations such as KADs, given that most have had limited racial and ethnic socialization experiences particularly within their context of their adoptive families.

All three hypotheses will be tested using participant age as a covariate, given the increased attention to racial and cultural socialization over the last two decades, and the creation of more resources specifically for transracially adoptive families (see Lee, 2003). It should be noted that due to the exploratory nature of the study, there is no specific hypothesis at the parameter level; however, invariance testing will be conducted to pinpoint the presence of nonequivalent friendships (if identified) based on early ethnic identity status. Use of structural equation path modeling will also allow for testing the significance of any indirect effects of racial in-exposure and ethnic heritage socialization on participants' current intragroup friendships through the hypothesized mediator of early intragroup contact.

\section{Method}

\section{Participants}

The dataset for this study is based on a larger international study on adult KADs, which originally involved 451 participants from 11 countries. For the purpose of the current study, only participants raised in the United States were included, which resulted in a total of 389 participants. Participant age was recorded according to three age groups: 29 and under $(n=168,43.19 \%), 30$ to $39(n=127,32.81 \%)$, and 40 and older $(n=104,25.84 \%)$. Females represented $82 \%$ of the sample and males represented only $18 \%$. Nearly all participants identified the race of 
both of their adoptive parents as Euro-Caucasian (98\%) and almost half indicated that they had at least one, nonbiological sibling also adopted from Korea (47\%).

\section{Recruitment}

Recruitment and data collection procedures took place using electronic email and Internet software, Survey Monkey. Initial recruitment began based on identifying and contacting nine organizations, eight of which were specific to adult KADs and one international adoption agency. Six of the nine organizations were based in the United States (four on the West coast, one on the East Coast, and one in the Midwest), whereas the remaining three were international organizations with headquarters located on the West Coast of the United States or in Seoul, South Korea. All nine organizations agreed to participate by emailing the survey link to members of their listserv.

\section{Measures and Procedures}

The data collection instrument was originally constructed for use in the larger international study on adult KADs that was focused on socialization, ethnic identity, and place attachment. Ethnic heritage activities and racial inexposure served as the two criterion variables to represent early racial and cultural socialization. Engagement in early ethnic heritage activities was assessed by four items that asked participants to provide yes/no responses about their involvement in the following Korean-heritage activities growing up: (a) culture camp, (b), language classes, (c) Korean immersion school, and (d) other types of exposure (celebrating holidays, food, cultural items in the home). Responses were coded dichotomously $(0=$ no and $1=y e s)$ and then tallied to provide the overall cultural exposure score, which could range from 0 to 4 . Racial in-exposure was based on demographic estimates of the city where participants reported growing up. Specifically, percentages ( 0 to $100 \%$ ) of White Americans were taken from U.S. Census data and converted to units ranging from 0 to 10 . The moderator variable, ethnic identity was assessed by one dichotomous item that asked participants whether or not they identified or considered themselves "Korean" growing up $(0=n o$ and $1=y e s)$ To assess the mediating variable of early intragroup contact, participants were asked to provide yes/no responses to four items that asked whether or not they had contact with the following growing up: (a) KADs, (b), non-adopted Koreans, (c) families with other KADs, and (d) siblings adopted from Korea. Responses were coded dichotomously $(0=n o$ and $1=y e s)$ and tallied to provide the overall early intragroup contact score which could range from 0 to 4 . The two outcome variables of current intragroup friendship was assessed based on two items that asked participants how often they personally interact with a) other adult KADs and b) non-adopted Koreans on a 3-point scale (1 = never to $3=a$ lot $)$.

AMOS software using structural equation modeling was used to test the first two hypotheses: a) a path model to determine that when controlling for participant age, whether the two early socialization variables accounted for participants' adult intragroup friendships and b) a mediation model to determine whether early intragroup contact mediated this relationship. Models were evaluated using several goodness-of-fit measures that included the Comparative fit index (CFI; considered best if .95 and greater; good at .90 and greater), standardized root-meansquare residual (SRMR; best if .08 or less; see Bentler, 1990; Hu \& Bentler, 1999), the root-mean-error of approximation (RMSEA; best if .06 or less, good if .08 or less, and acceptable if .10 or less). The significance levels of the mediation effects were assessed along with the indirect effects of the two early ethnic and racial socialization variables. To address the third hypothesis, invariance testing was used to assess whether the model functioned similarly depending on ethnic identity status. If the overall model is found non-invariant, post-hoc invariance testing will be used to determine the parameters that are significantly different based on ethnic identity status. 


\section{Results}

\section{Preliminary Analysis}

Table 1 presents the means, standard deviations, and zero-order correlations among study variables across the two identity groups. A total of 189 participants identified as Korean growing up (Identifiers) and 200 participants did not identify as Korean growing up (Non-identifiers). With the exception of participant age, all study variables were significantly related and in the same direction for both participant groups. The negative relationships between participant age and ethnic heritage activities as well as age and KAD friendships were significant for participants who identified as Korean whereas these relationships were not significant for non-identifiers. Relationships between age and friendships with nonadopted Koreans were not significant for both identity groups.

Table 1

Zero-Order Correlations, Means, and Standard Deviations of Study Variables

\begin{tabular}{|c|c|c|c|c|c|c|}
\hline Measure & 1. & 2. & 3. & 4. & 5. & $M(S D)$ \\
\hline \multicolumn{7}{|l|}{ Identifiers $(n=189)$} \\
\hline \multicolumn{7}{|l|}{ 1. Age } \\
\hline 2. Ethnic heritage activities & $-.22^{* *}$ & & & & & $2.24(.46)$ \\
\hline 3. Racial in-exposure & $.16^{*}$ & $-.24^{*}$ & & --- & & $8.17(.68)$ \\
\hline 4. Early intragroup contact & $-.33^{* *}$ & $.36^{* *}$ & $-.29^{* * *}$ & & & $2.27(.47)$ \\
\hline 5. KAD friendships & $-.29^{* *}$ & $.38^{* *}$ & $-.29^{\star * *}$ & $.29^{\star *}$ & & $2.23(.59)$ \\
\hline 6. Nonadopted Korean friendships & -.13 & $.35^{\star *}$ & $-.26^{\star * *}$ & $.30^{* *}$ & $.22^{\star *}$ & $2.12(.55)$ \\
\hline \multicolumn{7}{|l|}{ Non-Identifiers $(n=200)$} \\
\hline \multicolumn{7}{|l|}{ 1. Age } \\
\hline 2. Ethnic heritage activities & -.11 & & & & & $1.96(.49)$ \\
\hline 3. Racial in-exposure & $.16^{*}$ & $-.22^{* *}$ & --- & & & $8.58(.57)$ \\
\hline 4. Early intragroup contact & $-.17^{*}$ & $.16^{*}$ & $-.32^{\star * *}$ & & & $1.91(.43)$ \\
\hline 5. KAD friendships & -.08 & $.19^{* *}$ & $-.30^{* *}$ & $.29^{\star * *}$ & & $1.97(.57)$ \\
\hline 6. Nonadopted Korean friendships & -.09 & $.25^{\star *}$ & $-.31^{* * *}$ & $.28^{* * *}$ & $.16^{*}$ & $1.90(58)$ \\
\hline
\end{tabular}

${ }^{*} p<.05 .{ }^{* *} p<.01 .{ }^{* * *} p<.001$.

In addition, independent $t$-tests and Cohen's $d$ were calculated to assess differences between the two groups across the variables of interest and the strength of effect size. Results suggest that the two groups differed significantly across all study variables and indicated the strength of these differences were moderate to large (Cohen, 1992). Specifically, identifiers reported engaging in significantly more ethnic heritage activities $t(384)=-5.95, p<$ .001. (Cohen's $d=.58)$, intragroup contact $t(384)=-6.99, p<.001(d=-.37)$, current KAD friendships $t(384)=-$ $3.22, p<.001(d=.44)$, and friendships with nonadopted Koreans $t(384)=-2.91, p<.004(d=.38)$. Non-identifiers indicated significantly more racial in-exposure than identifiers $t(384)=6.99, p<.001(d=-.65)$.

\section{Path Analysis}

Hypothesis 1 tested a basic path model that simultaneously examined the impact of early ethnic heritage activities and racial in-exposure on participants' current friendships with KADs and nonadopted Koreans when controlling for participant age. Results of the omnibus Chi-square test suggested the model provided a sufficient fit for the data $\left(\mathrm{X}^{2}(3)=6.69, p<.08, \mathrm{CFI}=.99\right.$, SRMR $=.02$, RMSEA $=.05,95 \% \mathrm{Cl}[.00, .11]$, and that both early socialization variables had a statistically significant impact on the two outcome variables, such that ethnic heritage activities positively and significantly influenced current friendships with nonadopted Koreans $(b=.25, p<.001)$ and 
KADs $(b=.29, p<.001)$; and racial in-exposure negatively and significantly influenced current friendships with nonadopted Koreans $(b=-.29, p<.001)$ and KADs $(b=-.25, p<.001)$ (see Figure 1$)$. These results support Hypothesis 1 , which enabled the next step of mediation.

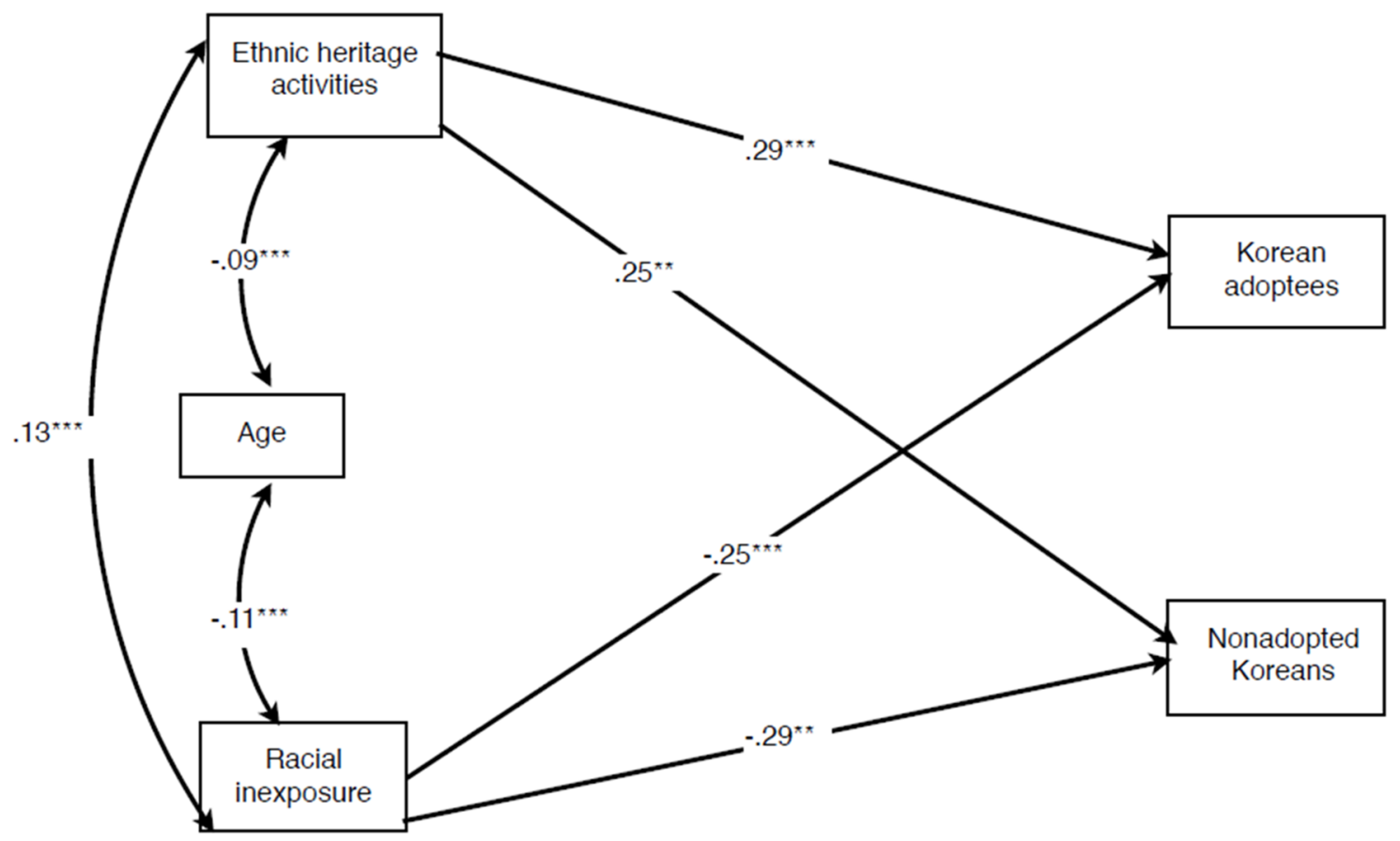

Figure 1. Unstandardized estimates for the single group path model.

To address Hypothesis 2, early intragroup contact was added to the model to examine the mediation effect in the relationship between the two early socialization variables (ethnic heritage activities and racial in-exposure) and the two adult intragroup socialization variables (friendships with KADs and with nonadopted Koreans) when controlling for age. Results suggest the mediation model provided a sufficient fit for the data $\mathrm{X}^{2}(3)=2.28, p<.52$, $\mathrm{CFI}=1.00, \mathrm{SRMR}=.01, \mathrm{RMSEA}=.00, \mathrm{Cl}[.00, .08]$. At the parameter level, all paths were statistically significant at the $p<.01$ level which provides preliminary evidence for the partial mediating effects of intragroup contact.

To test the significance of the partial mediation effects of intragroup contact in the relationship between ethnic heritage activities and racial in-exposure on current friendships with KADs and nonadopted Koreans, random sampling was used to create 1000 bootstrap samples with replacement. From the covariance matrices of the 1000 bootstrap samples, the product terms of path coefficients were used to obtain 1000 set of indirect effects. Given that the distribution of product terms tend to be skewed for normally distributed variables (Mallinckrodt, Abraham, Wei, \& Russell, 2006), 95\% bias-corrected confidence levels were created from the 1000 set of indirect effects to ensure symmetry. To determine the significance of the indirect effects, confidence intervals were examined for the exclusion of zero; indicative of a statistically significant indirect effect at the .05 level. As shown in Figure 2 , the indirect effects of ethnic heritage activities on KAD friendships $(.04,95 \% \mathrm{Cl}[.01, .08])$ and nonadopted Koreans $(.02,95 \% \mathrm{Cl}[.01, .05])$ were significant, as were the indirect effects of racial in-exposure on current friendships with KADs $(-.09,95 \% \mathrm{Cl}[-.14,-.05])$ and nonadopted Koreans (-.05, 95\% Cl [-.09, -.01]). Results support Hypothesis 2 in that early intragroup contact partially mediated the effects of ethnic heritage activities and racial in-exposure on participants' current intragroup friendships. 


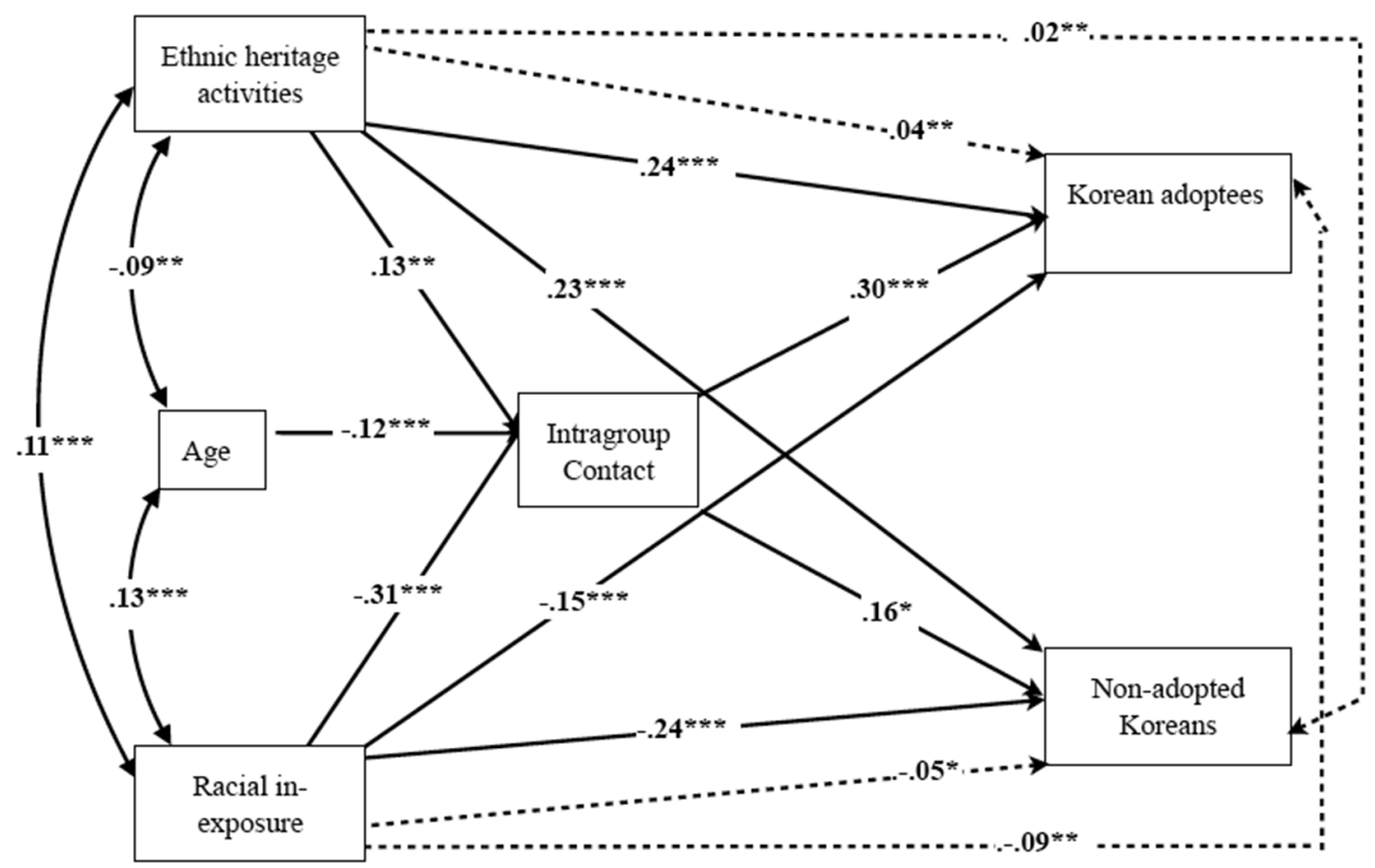

Figure 2. Standardized estimates of the mediated single group model.

\section{Multigroup Path Analysis}

Prior to testing Hypothesis 3, preliminary tests were conducted to determine the consistency of the basic model structure by testing each group separately (Byrne, 2004). The results revealed acceptable fit statistics for both identifiers and non-identifiers, indicating initial model consistency (see Table 2). To address Hypothesis 3, multigroup path analysis was used to test whether the mediation model functioned similarly across both groups of participants based on whether or not they identified as Korean growing up. First, a freely estimated baseline model was tested which allowed all parameters to vary across the two groups. Goodness of fit statistics suggested the unconstrained model provided a sufficient fit for the data $\mathrm{x}^{2}(6)=8.27, p<.004, \mathrm{CFI}=.99, \mathrm{SRMR}=.04, \mathrm{RMSEA}=.02,95 \% \mathrm{CI}$ $[.00, .07]$, which provided the baseline model for nested comparisons. Second, to determine whether the mediation model was invariant across groups, equality constraints were placed on all model parameters and compared to the baseline model. Results of the Chi-square difference test were statistically significant $\Delta \mathrm{x}^{2}(14)=30.27, p<$ .003 , indicating the presence of non-invariance across the two groups. Specifically, the fully restricted model significantly worsened model fit and fulfilled the overarching study hypothesis that the mediated socialization model operated differently depending on whether participants identified as Korean.

\section{Post-hoc Invariance Testing}

Although there was no specific hypothesis at the parameter level, post-hoc invariance testing was used to identify the non-invariant parameters across the two identity groups. As recommended by Byrne (2004), to identify noninvariant parameters, equality constraints were first placed on the model variances and covariances and then placed on the model regression paths. For both steps, the Chi-square difference test was used to identify any significant changes in $x^{2}$ compared to the baseline model to determine whether the constrained set of parameters were truly non-invariant. Results of the Chi-square different test indicated that constraining the model's variances 
and covariances as equal did not result in a significant degree of change from the baseline model $\Delta x^{2}(5)=10.20$ $p<.08$; however, imposing equality constraints on the model's regression paths, significantly worsened model fit $\Delta \mathrm{X}^{2}(9)=20.07, p<.03$ revealing the presence of non-invariant pathways.

To identify the non-invariant pathways across the two groups, fit statistics were calculated for nine separate models. For each model, equality constraints were placed on each individual parameter and changes in Chi-square were assessed for worsening of model fit (see Table 2). From this series of testing, Chi-square difference tests revealed two non-invariant pathways across the two identity groups: the path from ethnic heritage activities to early intragroup contact $\Delta \mathrm{x}^{2}(2)=7.80, p<.03$ and from ethnic heritage activities to friendships with $\operatorname{KADs}\left(\Delta \mathrm{x}^{2}(2)\right.$ $=7.73, p<.05)$. Ethnic heritage activities had a significantly stronger impact on early intragroup contact for identifiers (.22) compared to participants who did not identify as Korean (-.01); whereas the effect of ethnic heritage activities on friendships with KADs was significantly stronger for participants identified as Korean (.34), compared to identifiers (.15).

Table 2

Goodness-of-Fit Indices and Results of Invariance Testing

\begin{tabular}{|c|c|c|c|c|c|c|c|}
\hline Model Description & $x^{2}$ & $d f$ & $\Delta \mathrm{x}^{2}$ & $\Delta d f$ & CFI & RMSEA [Cl] & SRMR \\
\hline Identifiers & .59 & 3 & & & .99 & $.01[.00, .05]$ & .01 \\
\hline Non-identifiers & 4.64 & 3 & & & .98 & $.05[.02, .14]$ & .03 \\
\hline Unconstrained multi-group baseline model & 8.27 & 6 & & & .99 & $.02[.00, .07]$ & .04 \\
\hline Full constraints all parameters & 38.54 & 20 & $30.27^{* *}$ & 14 & .94 & $.05[.02, .07]$ & .07 \\
\hline Variances and covariances constrained as equal & 18.47 & 11 & 10.20 & 5 & .98 & $.04[.00, .07]$ & .04 \\
\hline Paths constrained as equal & 28.32 & 15 & $20.07^{*}$ & 9 & .96 & $.05[.01, .07]$ & .07 \\
\hline \multicolumn{8}{|l|}{ Post-hoc Invariance Testing of Model Pathways } \\
\hline Model Description & $x^{2}$ & $d f$ & $\Delta \mathrm{x}^{2}$ & $\Delta d f$ & CFI & RMSEA [Cl] & SRMR \\
\hline 1. Racial in-exposure $\rightarrow$ KADs & 15.98 & 7 & 1.64 & 1 & .99 & $.04[.00, .07]$ & .05 \\
\hline 2. Model $1 \&$ ethnic heritage $\rightarrow$ intragroup contact & 9.88 & 8 & $7.80^{*}$ & 2 & .99 & $.03[.00, .07]$ & .04 \\
\hline 3. Model 1 \& ethnic heritage $\rightarrow$ KADs & 15.98 & 8 & $7.73^{*}$ & 2 & .99 & $.04[.00, .07]$ & .05 \\
\hline 4. Model $1 \&$ racial in-exposure $\rightarrow$ nonadopted Koreans & 16.05 & 8 & 4.07 & 2 & .98 & $.05[.00, .08]$ & .05 \\
\hline 5. Model $4 \&$ ethnic heritage $\rightarrow$ nonadopted Koreans & 12.32 & 9 & 6.85 & 3 & .98 & $.03[.00, .07]$ & .05 \\
\hline 6. Model $5 \&$ racial in-exposure $\rightarrow$ intragroup contact & 15.20 & 10 & 6.95 & 4 & .99 & $.03[.00, .06]$ & .05 \\
\hline 7. Model 6 \& intragroup contact $\rightarrow$ KADs & 15.20 & 11 & 6.96 & 4 & .99 & $.03[.00, .06]$ & .05 \\
\hline 8. Model 7 \& intragroup contact $\rightarrow$ nonadopted Koreans & 17.20 & 12 & 8.95 & 6 & .99 & $.02[.00, .06]$ & .05 \\
\hline 9. Model $8 \&$ age $\rightarrow$ intragroup contact & 20.40 & 13 & 12.15 & 7 & .98 & $.03[.00, .06]$ & .05 \\
\hline
\end{tabular}

${ }^{*} p<.05 .{ }^{* *} p<.01 .{ }^{* *} p<.001$.

To elucidate additional information about the mediational effects across identifiers (see Figure 3) and non-identifiers (see Figure 4), the model pathways were further examined. Early intragroup contact partially mediated the effects of racial in-exposure on current friendships with KADs and nonadopted Koreans for non-identifiers; and partially mediated the effect on friendships with nonadopted Koreans for identifiers. In addition, intragroup contact fully mediated the effect of racial in-exposure on participants' KAD friendships for identifiers. For participants that did not identify as Korean, ethnic heritage activities did not significantly impact their intragroup contact; whereas intragroup contact partially mediated the relationship between ethnic heritage activities and friendships with KADs and nonadopted Koreans. Results from the bootstrap analysis suggested that the indirect effects of early racial in-exposure had a significant impact on identifiers' friendships with KADs (-.08, Cl 95\% [-.15, -.03] and nonadopted Koreans $(.05,95 \% \mathrm{Cl}[.03, .15])$. For non-identifiers, the indirect effects of racial in-exposure on current KAD 
friendships were also statistically significant $(-.07,95 \% \mathrm{Cl}[-.14,-.02])$ as were the indirect effects on friendships with nonadopted Koreans (-.06, 95\% $\mathrm{Cl}[-.15,-.01])$. The indirect effects of ethnic heritage activities, however, were only statistically significant on identifiers' current $\operatorname{KAD}$ friendships $(.07,95 \% \mathrm{Cl}[.03, .15])$.

In addition, the total effects of ethnic heritage activities, early intragroup contact, and racial in-exposure were examined across the two groups. For identifiers, the three early socialization variables accounted for a total of $57 \%$ of the variance in current friendships with non-adopted Koreans and $59 \%$ of the variance in KAD friendships. For non-identifiers, the three early socialization variables accounted for $64 \%$ of the variance in current friendships with nonadopted Koreans and $56 \%$ of the variance in current KAD friendships. For both groups, the total effects of racial in-exposure were large (identifiers $=69 \%$; non-identifiers $=80 \%$ ); whereas the total effects of ethnic heritage activities were stronger for identifiers (70\%) compared to participants that did not identify as Korean (38\%). Intragroup contact appeared to have similar overall effects for participants that identified as Korean (36\%) versus participants that did not identify as Korean (34\%).

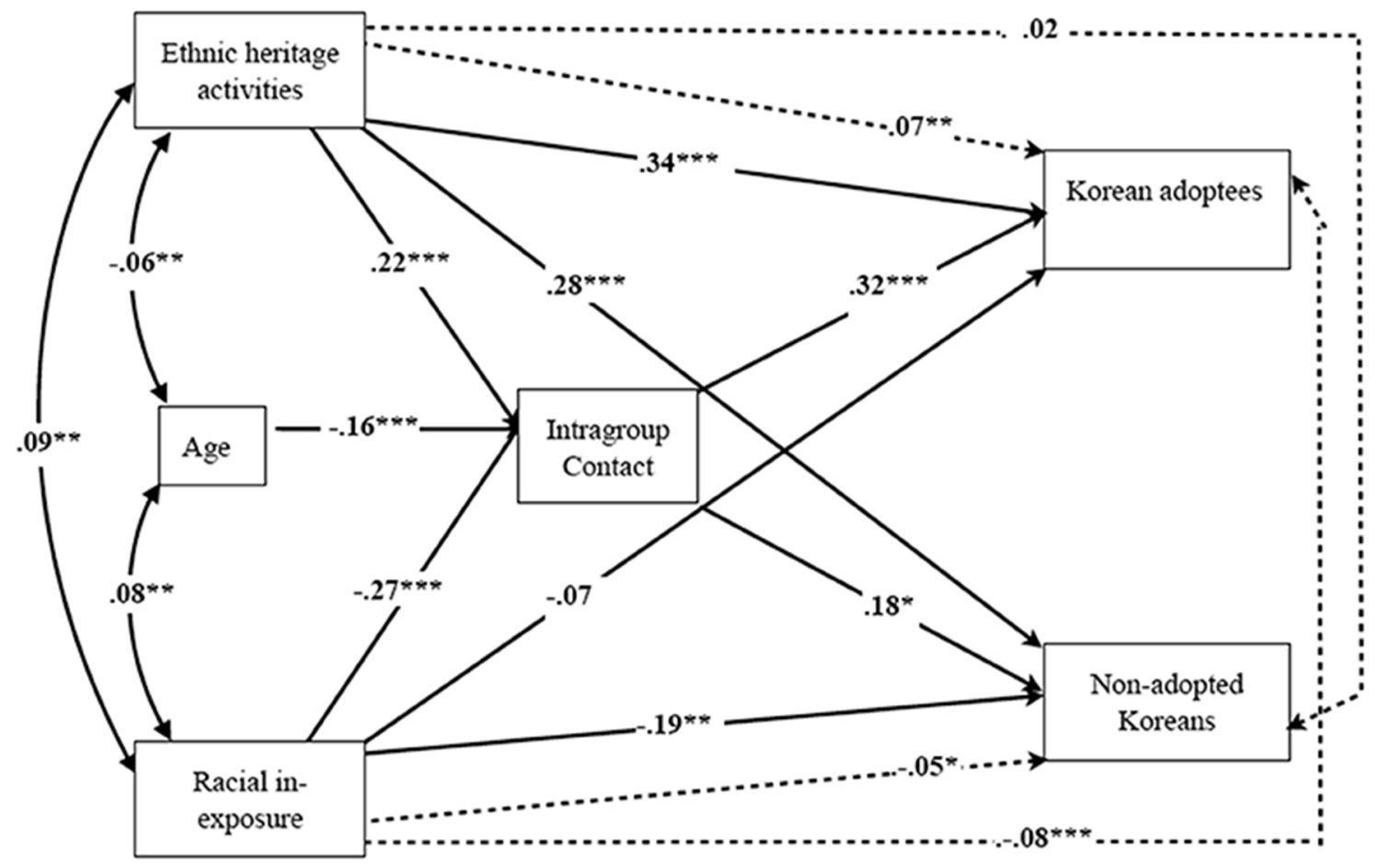

Figure 3. Standardized estimates of the mediated multi-group path model for identifiers (participants who identified as Korean). 


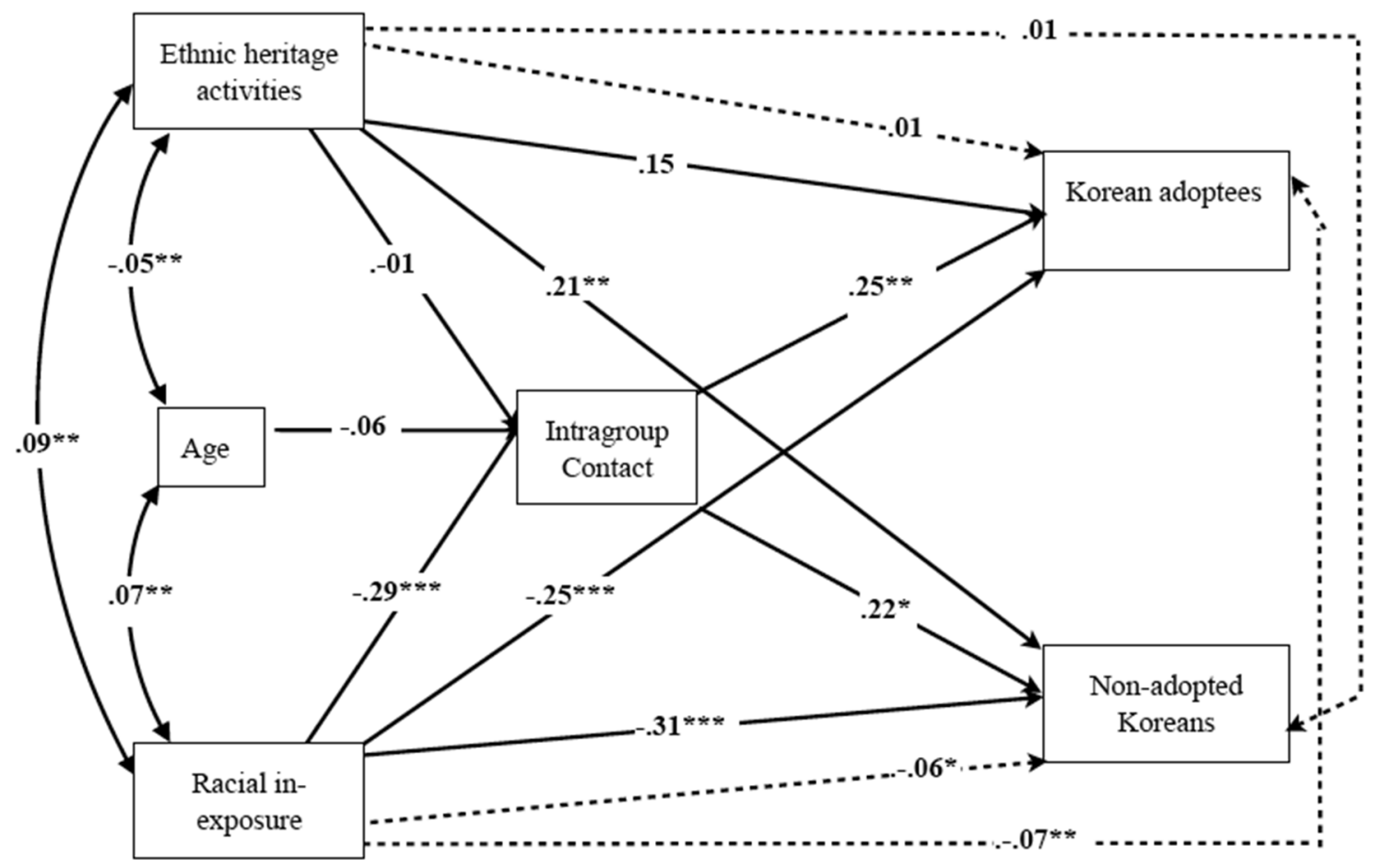

Figure 4. Standardized estimates of the mediated multi-group path model for non-identifiers (participants who did not identify as Korean).

\section{Discussion}

This study examined whether exposure to early ethnic heritage activities and residence in racially un-integrated areas accounted for a sample of adult KADs self-reported friendships with other KADs and nonadopted Koreans. Based on the principle of homophily that suggests people tend to gravitate toward similar others (McPherson et al., 2001), intragroup contact was included as a mediator variable to elucidate the explanatory role in this relationship. Using multigroup analysis, it was also hypothesized that this relationship would differ depending on participants' early ethnic identity status, such that the model would function differently across the two identity groups. Given the exploratory nature of this study, there was no specific hypothesis at the parameter level and post-hoc invariance testing was used to identify the presence of unequal parameters. This is one of the first studies to examine the concepts of ethnic identity and intragroup socialization for KADs or other transracial adoptees within a greater ecological context beyond the adoptive family. In addition to addressing the moderating role of ethnic identity, we examined other indicators of socialization, such as personal relationships with other KADs and nonadopted Koreans to examine ways that KADs might connect with members of their ethnic group.

Overall, it appears that when controlling for participant age, early involvement in ethnic heritage activities positively accounted for more personal friendships with other KADs and nonadopted Koreans; while living in racially un-integrated areas negatively accounted for their ethnic friendships. In particular, participating in culture camps, language lessons, and other ethnic heritage activities positively influenced participants' current personal friendships with Koreans, despite the significant and negative impact of growing up in racially un-integrated areas. When entered as a mediator, intragroup contact partially explained this relationship such that ethnic heritage activities and racial 
in-exposure indirectly influenced participants' current friendships with KADs and nonadopted Koreans. This suggests that engaging in ethnic heritage activities and living in racially homogenous areas had a significant impact on participants' early contact with other Koreans which in turn, accounted for their current friendships with KADs and nonadopted Koreans. These findings are consistent with the organizing principle of homophily which suggests that similarity breeds connection and is based on geographic propinquity, relational contexts, and other organizing systems (McPherson et al., 2001). At the same time, the direct impact of ethnic heritage activities and racial inexposure on both outcome variables remained significant even with the addition of intragroup contact, which could indicate the presence of other explanatory variables and/or that living in racially un-integrated areas and early ethnic socialization had a significant and long-term impact, above and beyond early interactions with Koreans.

At the multigroup level, however, results suggest that this was not the case for all sample participants, particularly when accounting for early ethnic identity status. In particular, engaging in different levels of ethnic heritage activities appeared to have varying effects on participants' early intragroup contact as well as longer-term intragroup friendships. Results of invariance testing suggested that ethnic heritage activities had a larger impact on identifiers' early intragroup contact compared to non-identifiers. Specifically, ethnic heritage activities accounted for $70 \%$ of the variance in the model for participants that identified as Korean and only $38 \%$ for non-identifiers. These findings are consistent with previous research on young KADs, which suggests that KADs with early exposure to aspects of their culture, have also described strong feelings of connection to Korean culture (Lee \& Quintana, 2005; Yoon, 2000). Compared to non-identifiers, identifiers engaged in more ethnic heritage activities $(M=2.24$ vs. $M=1.96)$ and had more contact with Koreans $(M=2.27$ vs. $M=1.91)$. Based on the tenants of social identity theory, it is possible that participants who identified as Korean had more motivation or desire to engage in ethnic heritage activities, which enabled more opportunities to interact with members of their ethnic group which highlighted a sense of social and collective identity. In addition, ethnic heritage activities had a greater long-term impact for identifiers, such that they were more likely to be friends with KADs as adults. Compared to participants that did not identify as Korean, identifiers may have placed more meaning on their involvement in ethnic heritage activities, which carried over to their early and longer-term friendships. These results may speak to the significance of early cultural socialization in forming initial patterns of homophily, as these opportunities provided the racial and ethnic (intragroup) exposure that was absent in their day-to-day lives. Non-identifiers may have still participated in culture camp or language classes; however, they may have been less motivated to develop connections with Koreans considering that their ethnic identity was less salient or meaningful for them at that time.

In addition, early intragroup contact had different mediational effects for participants depending on identity status. For participants who identified as Korean, their early experiences with intragroup contact fully explained the effect of growing up in primarily White homogenous areas on their friendships with KADs; whereas intragroup contact partially explained the effect of racial inexposure on friendships with KADs. For participants that did not identify as Korean, it is possible that additional variables beyond early intragroup contact explains the reasons why living in racially un-integrated areas would negatively impact the likelihood of participants developing personal friendships with other KADs. All participants, regardless of early ethnic identity status, faced subsequent life events (related or nonrelated to their ethnicity), that may have facilitated their desire to connect with similar others. For adoptees, life experiences such as college, developing romantic friendships, and starting a family have been found to elicit existential questions about their identity in relation to others (Grotevant, 2000).

Despite these differences, the proposed model was similar in several ways across the two identity groups. In particular, ethnic heritage activities positively accounted for participants' current friendships with nonadopted 
Koreans; and racial in-exposure had similar effects on participants' early intragroup contact and current friendships with nonadopted Koreans. Regardless of ethnic identity status, growing up in primarily White, homogenous areas seemed to have the largest total effect on developing friendships with KADs and nonadopted Koreans particularly through the process of early intragroup contact. Both identifiers and non-identifiers grew up in racially un-integrated areas where Whites comprised the majority of the population $(82 \%=$ identifiers and $86 \%=$ non-identifiers $)$, which is consistent with prior research (Thornton, Chatters, Taylor, \& Allen, 1990). As visible minorities who must function in a majority-based environment, KADs may have defined themselves through their friendships and interactions in the broader society in which they lived (Phinney et al., 2001; Umaña-Taylor \& Fine, 2004). Despite their unique experiences with racial and ethnic socialization growing up, KADs in the current study appeared to demonstrate relational preferences consistent with the principle of homophily and social identity theory. Consistent with patterns of homophily, KADs who grew up in racially un-integrated areas also had less contact with KADs and nonadopted Koreans; however, exposure to ethnic heritage activities seemed to increase the likelihood for contact. Having a greater sense of awareness as a visible minority, may have pushed KADs to seek out more cultural socialization opportunities, which helped foster an immediate and long term connection with other Koreans.

\section{Limitations}

Findings from this study should be interpreted in the context of several limitations due to sampling bias, likelihood for measurement error, and the cross-sectional nature of the research. Given the selectiveness of the study sample, study results are only applicable to this sample of adult KADs and cannot be generalized to the greater KAD or transracial adoptee population. Furthermore, recruiting participants from organized adult adoptee groups increased the chance that participants were already affiliated with organized networks specifically for KADs. Compared to KADs unassociated with adoptee organizations, KADs in this sample may have had more opportunities to establish relationships with other KADs based on their involvement alone. It is possible that KADs who are unaffiliated with organized adoptee groups have markedly different experiences with socialization, which may account for their non-involvement.

In addition, based on the measures used, measurement error could have influenced study results. In particular, measures used to assess ethnic identity and intragroup friendships were created for the purposes of this study without evidence of psychometric support. Several items were assessed dichotomously and failed to account for the varying degrees of involvement in ethnic heritage activities or ethnic identity status. Assessing ethnic identity on a rating-scale may have provided nuanced information about the nature of the moderating effect in the relationship between early socialization and adult intragroup friendships. And finally, as a cross-sectional study, causation cannot be fully inferred from participants' early socialization experiences on their early intragroup contact or their adult friendships. Results were based on participants' retrospective reports of their ethnic and racial socialization experiences which may have been diminished or skewed based on various encounters throughout their lifetime.

In summary, the results of this study speak to the significance of cultural socialization and ecological factors that can affect social identity development and help elucidate the principle of homophily among a unique ethnic subgroup. Although KADs are part of the larger Korean and Asian American community, their unique experiences with intragroup socialization are likely to fluctuate with age and exposure.

\section{Funding}

The authors have no funding to report. 


\section{Competing Interests}

The authors have declared that no competing interests exist.

\section{Acknowledgments}

The authors have no support to report.

\section{References}

Abrams, D. (1996). Social identity, self as structure and self as process. In W. P. Robinson (Ed.), Social groups and identities: Developing the legacy of Henri Tajfel (pp. 143-167). Oxford, England: Butterworth-Heinemann.

Adams, R. G. (1987). Patterns of network change: A longitudinal study of friendships of elderly women. The Gerontologist, 27(2), 222-227. doi:10.1093/geront/27.2.222

Baden, A. L. (2002). The psychological adjustment of transracial adoptees: An application of the Cultural-Racial Identity Model. Journal of Social Distress and the Homeless, 11, 167-191. doi:10.1023/A:1014316018637

Bentler, P. M. (1990). Comparative fit indexes in structural models. Psychological Bulletin, 107, 238-246. doi:10.1037/0033-2909.107.2.238

Brewer, M. B. (1991). The social self: On being the same and different at the same time. Personality and Social Psychology Bulletin, 17, 475-482. doi:10.1177/0146167291175001

Brooks, D., \& Barth, R. P. (1999). Adult transracial and inracial adoptees: Effects of race, gender, adoptive family structure, and placement history on adjustment outcomes. American Journal of Orthopsychiatry, 69, 87-99. doi:10.1037/h0080384

Byrne, B. M. (2004). Testing for multigroup invariance using AMOS graphics: A road less traveled. Structural Equation Modeling, 11, 272-300. doi:10.1207/s15328007sem1102_8

Clark, M. L., \& Ayers, M. (1992). Friendship similarity during early adolescence: Gender and racial patterns. The Journal of Psychology, 126, 393-405. doi:10.1080/00223980.1992.10543372

Cohen, J. (1992). A power primer. Psychological Bulletin, 112, 155-159. doi:10.1037/0033-2909.112.1.155

Connidis, I. A., \& Davies, L. (1992). Confidants and companions: Choices in later life. Journal of Gerontology, 47(3), S115-S122. doi:10.1093/geronj/47.3.S115

Feigelman, W. (2000). Adjustments of transracially and inracially adopted young adults. Child and Adolescent Social Work Journal, 17, 165-183. doi:10.1023/A:1007531829378

Freundlich, M., \& Lieberthal, J. K. (2000). The gathering of the first generation of adult Korean adoptees: Adoptees' perceptions of international adoption (Report). Retrieved from Evan B. Donaldson Adoption Institute website: http://www.adoptioninstitute.org/proed/korfindings.html

Goldman, J. A. (1981). Social participation of preschool children in same- versus mixed-age groups. Child Development, 52 , 644-650. http://www.jstor.org/stable/1129185doi:10.2307/1129185

Goto, S. T. (1997). Nerds, normal people, and homeboys: Accommodation and resistance among Chinese American students. Anthropology \& Education Quarterly, 28(1), 70-84. doi:10.1525/aeq.1997.28.1.70 
Grotevant, H. D. (2000). Openness in adoption: Research with the adoptive kinship network. Adoption Quarterly, 4(1), 45-65. doi:10.1300/J145v04n01_04

Hamm, J. V. (2000). Do birds of a feather flock together? Individual, contextual, and relationship bases for African American, Asian American, and European American adolescents' selection of similar friends. Developmental Psychology, 36, $209-219$. doi:10.1037/0012-1649.36.2.209

Hartup, W. W., \& Stevens, N. (1997). Friendships and adaptation in the life course. Psychological Bulletin, 121, 355-370. doi:10.1037/0033-2909.121.3.355

Herman, M. (2004). Forced to choose: Some determinants of racial identification in multiracial adolescents. Child Development, 75, 730-748. doi:10.1111/j.1467-8624.2004.00703.x

Hess, B. (1972). Friendship. In M. W. Riley, M. Johnson, \& A. Foner (Eds.), Ageing and society (Vol. 3, pp. 357-393). New York, NY: Russell Sage Foundation.

Hochschild, A. (1973). The unexpected community. Englewood Cliffs, NJ: Prentice-Hall.

Hogg, M. A., \& Abrams, D. (1988). Social identifications: A social psychology of intergroup relations and group processes. London, England: Routledge.

Hogg, M. A., Abrams, D., \& Patel, Y. (1987). Ethnic identity, self-esteem, and occupational aspirations of Indian and Anglo-Saxon British adolescents. Genetic, Social, and General Psychology Monographs, 113, 487-508.

Howes, C., \& Wu, F. (1990). Peer interactions and friendships in an ethnically diverse school setting. Child Development, 61(2), 537-541. doi:10.2307/1131113

Hu, L.-t., \& Bentler, P. M. (1999). Cutoff criteria for fit indexes in covariance structure analysis: Conventional criteria versus new alternatives. Structural Equation Modeling, 6(1), 1-55. doi:10.1080/10705519909540118

Hübinette, T. (2004). Adopted Koreans and the development of identity in the 'third Space'. Adoption \& Fostering, 28(1), 16-24. doi:10.1177/030857590402800104

Huh, N. S., \& Reid, W. K. (2000). Intercountry, transracial adoption and ethnic identity: A Korean example. International Social Work, 43, 75-87.

Kim, G. S., Suyemoto, K. L., \& Turner, C. B. (2010). Sense of belonging, sense of exclusion, and racial and ethnic identities in Korean transracial adoptees. Cultural Diversity \& Ethnic Minority Psychology, 16, 179-190. doi:10.1037/a0015727

Langrehr, K. J., Yoon, E. J., Hacker, J., \& Caudill, K. (in press). Implications of transnational adoption status for adult Korean adoptees. Journal of Multicultural Counseling and Development.

Lee, D. C., \& Quintana, S. M. (2005). Benefits of cultural exposure and development of Korean perspective-taking ability for transracially adopted Korean children. Cultural Diversity \& Ethnic Minority Psychology, 11, 130-143. doi:10.1037/1099-9809.11.2.130

Lee, R. M. (2003). The transracial adoption paradox: History, research, and counseling implications of cultural socialization. The Counseling Psychologist, 31, 711-744. doi:10.1177/0011000003258087 
Lee, R. M., Grotevant, H. D., Hellerstedt, W., Gunnar, M., \& The Minnesota International Adoption Project Team. (2006). Cultural socialization in families with internationally adopted children. Journal of Family Psychology, 20, 571-580. doi:10.1037/0893-3200.20.4.571

Lee, R. M., \& Miller, M. J. (2009). History and psychology of adoptees in Asian America. In N. Tewari \& A. N. Alvarez (Eds.), Asian American Psychology: Current Perspectives (pp. 337-363). New York, NY: Psychology Press.

Mallinckrodt, B., Abraham, W. T., Wei, M., \& Russell, D. W. (2006). Advances in testing the statistical significance of mediation effects. Journal of Counseling Psychology, 53(3), 372-378. doi:10.1037/0022-0167.53.3.372

Matthews, H. (1995). Culture, environmental experience and environmental awareness: Making sense of young Kenyan children's views of place. The Geographical Journal, 161, 285-295. doi:10.2307/3059833

McCandless, B. R., \& Hoyt, J. M. (1961). Sex, ethnicity, and play preferences of preschool children. Journal of Abnormal and Social Psychology, 62, 683-685. doi:10.1037/h0045539

McGinnis, H., Smith, S. L., Ryan, S. D., \& Howard, J. A. (2009). Beyond culture camp: Promoting healthy identity formation in adoption (Report). Retrieved from Evan B. Donaldson Adoption Institute website:

http://adoptioninstitute.org/publications/beyond-culture-camp-promoting-healthy-identity-formation-in-adoption

McPherson, M., Smith-Lovin, L., \& Cook, J. M. (2001). Birds of a feather: Homophily in social networks. Annual Review of Sociology, 27, 415-444. doi:10.1146/annurev.soc.27.1.415

Meier, D. I. (1999). Cultural identity and place in adult Korean-American intercountry adoptees. Adoption Quarterly, 3, 15-48. doi:10.1300/J145v03n01_03

Mohanty, J., Keokse, G., \& Sales, E. (2006). Family cultural socialization, ethnic identity, and self-esteem: Web-based survey of international adult adoptees. Journal of Ethnic and Cultural Diversity in Social Work, 15, 153-172. doi:10.1300/J051v15n03_07

National Association of Korean Americans. (n.d.). In Observance of Centennial of Korean Immigration to the U.S. Retrieved from http://www.naka.org/resources/history.asp

Phinney, J. S., Romero, I., Nava, M., \& Huang, D. (2001). The role of language, parents, and peers in ethnic identity among adolescents in immigrant families. Journal of Youth and Adolescence, 30(2), 135-153. doi:10.1023/A:1010389607319

Samuels, G. M. (2009). "Being raised by white people": Navigating racial difference among adopted multiracial adults. Journal of Marriage and the Family, 71(1), 80-94. doi:10.1111/j.1741-3737.2008.00581.x

Scroggs, P. H., \& Heitfield, H. (2001). International adopters and their children: Birth culture ties. Gender Issues, 19(4), 3-30. doi:10.1007/s12147-001-1005-6

Shiao, J. L., \& Tuan, M. H. (2008). Korean adoptees and the social context of ethnic exploration. American Journal of Sociology, 113, 1023-1066. doi:10.1086/522807

Simon, R. J., \& Altstein, H. (2000). Adoption across borders: Serving the children in transracial and intercountry adoptions. Lanham, MD: Rowman \& Littlefield.

Tajfel, H. (1981). Social stereotypes and social groups. In J. C. Turner (Ed.), Intergroup behaviour (pp. 144-167). Oxford, United Kingdom: Blackwell. 
Tajfel, H., \& Turner, J. C. (1986). The social identity theory of intergroup behavior. In S. Worchel \& W. G. Austin (Eds.), Psychology of intergroup relations. Chicago, IL: Nelson-Hall.

Tatum, B. D. (1999). Why are all the black kids sitting in the cafeteria together? New York, NY: Basic Books.

Thornton, M. C., Chatters, L. M., Taylor, R. J., \& Allen, W. R. (1990). Sociodemographic and environmental correlates of racial socialization by Black parents. Child Development, 61, 401-409. doi:10.2307/1131101

Umaña-Taylor, A. J., \& Fine, M. A. (2004). Examining ethnic identity among Mexican-origin adolescents living in the United States. Hispanic Journal of Behavioral Sciences, 26, 36-59. doi:10.1177/0739986303262143

Westhues, A., \& Cohen, J. S. (1998). Ethnic and racial identity of internationally adopted adolescents and young adults: Some issues in relation to children's rights. Adoption Quarterly, 1(4), 33-55. doi:10.1300/J145v01n04_03

Wickes, K. L., \& Slate, J. R. (1996). Transracial adoption of Koreans: A preliminary study of adjustment. International Journal for the Advancement of Counselling, 19(2), 187-195. doi:10.1007/BF00114788

Wood, L. F., \& Pannen, D. E. (1996). The natural history of friendship dissolution: A cross-sectional view of men and women. Paper presented at the Meeting of the International Network on Personal Friendships, Seattle, WA.

Yoon, D. P. (2000). Causal modeling predicting psychological adjustment of Korean-born adolescent adoptees. Journal of Human Behavior in the Social Environment, 3, 65-82. doi:10.1300/J137v03n03_06 